\title{
Ubiquitin-Mediated Regulation of Endocytosis by Proteins of the Arrestin Family
}

\author{
Michel Becuwe, ${ }^{1}$ Antonio Herrador, ${ }^{2}$ Rosine Haguenauer-Tsapis, ${ }^{1}$ \\ Olivier Vincent, ${ }^{2}$ and Sébastien Léon ${ }^{1}$ \\ ${ }^{1}$ Institut Jacques Monod, Centre National de la Recherche Scientifique, UMR 7592, Université Paris Diderot, Sorbonne Paris Cité,
75205 Paris, France
${ }^{2}$ Instituto de Investigaciones Biomédicas, CSIC-UAM, Arturo Duperier, 4, 28029 Madrid, Spain
}

Correspondence should be addressed to Olivier Vincent, ovincent@iib.uam.es

and Sébastien Léon, leon.sebastien@ijm.univ-paris-diderot.fr

Received 1 June 2012; Accepted 28 July 2012

Academic Editor: Dmitry Karpov

Copyright (C) 2012 Michel Becuwe et al. This is an open access article distributed under the Creative Commons Attribution License, which permits unrestricted use, distribution, and reproduction in any medium, provided the original work is properly cited.

\begin{abstract}
In metazoans, proteins of the arrestin family are key players of G-protein-coupled receptors (GPCRS) signaling and trafficking. Following stimulation, activated receptors are phosphorylated, thus allowing the binding of arrestins and hence an "arrest" of receptor signaling. Arrestins act by uncoupling receptors from $\mathrm{G}$ proteins and contribute to the recruitment of endocytic proteins, such as clathrin, to direct receptor trafficking into the endocytic pathway. Arrestins also serve as adaptor proteins by promoting the recruitment of ubiquitin ligases and participate in the agonist-induced ubiquitylation of receptors, known to have impact on their subcellular localization and stability. Recently, the arrestin family has expanded following the discovery of arrestin-related proteins in other eukaryotes such as yeasts or fungi. Surprisingly, most of these proteins are also involved in the ubiquitylation and endocytosis of plasma membrane proteins, thus suggesting that the role of arrestins as ubiquitin ligase adaptors is at the core of these proteins' functions. Importantly, arrestins are themselves ubiquitylated, and this modification is crucial for their function. In this paper, we discuss recent data on the intricate connections between arrestins and the ubiquitin pathway in the control of endocytosis.
\end{abstract}

\section{Introduction}

The name of "arrestin" was initially given to a $48-\mathrm{kDa}$ protein that was essential to "arrest" the signal following the photoexcitation of rhodopsin, a photoreceptor of the Gprotein-coupled receptors (GPCRS) family expressed in rod and cone cells of the retina $[1,2]$. A second isoform involved in the same process has later been identified; both of these proteins are now designated visual arrestins (or arrestin-1 and -4) (for review see [3]). A similar regulatory system was described for another GPCR, the $\beta 2$-adrenergic receptor $(\beta 2$ AR), which involves two other arrestins, named $\beta$-arrestin1 and -2 (or arrestin-2 and -3, resp.) [4-6]. $\beta$-arrestins are ubiquitously expressed and were later found to regulate a large number of receptors in addition to $\beta 2$-AR.

\section{Arrestin-Mediated Regulation of GPCRs}

2.1. Arrestin-Dependent Uncoupling of GPCRs from GProteins. Arrestins are key players in the regulation of GPCR signaling activity. Upon agonist stimulation, GPCRs undergo conformational changes leading to their association to heterotrimeric $G$ proteins and subsequent activation, thereby triggering appropriate signal transduction pathways. Receptor desensitization is initiated after ligand binding through the phosphorylation of residues within their cytosolic loops by G-protein-coupled receptor kinases (GRKs). This modification allows arrestin docking to the GPCR, which in turn favors the uncoupling between the receptor and the $\mathrm{G}$ protein. Indeed, $\beta$-arrestins are cytosolic proteins that, in response to receptor stimulation, relocalize rapidly to 
the plasma membrane [7]. Structural and structure-function studies of visual arrestins identified a phosphate-sensor domain in the polar core of the protein [8]. Intramolecular interactions between the C-terminal tail and the phosphate sensor region maintain the arrestin in an inactive state, and this interaction is disrupted upon binding to the phosphorylated receptor. This interaction is followed by a conformational change of the arrestin molecule and leads to a high-affinity receptor-binding state. Arrestin recruitment onto the phosphorylated receptor hinders its interaction with $G$ protein, and consequently silences the activation of the GPCR-G protein-signaling module.

2.2. Arrestins and GPCR Endocytosis. Another crucial component of GPCR regulation operates at the level of their localization [9]. Endocytosis plays a major role in the modulation of GPCR signaling activity, and, again, this regulation involves $\beta$-arrestins [10]. Indeed, $\beta$-arrestins act as endocytic adaptor proteins that recruit components of the endocytosis machinery to promote GPCR internalization and/or degradation. $\beta$-arrestins interact with clathrin through a clathrin-binding motif [11-13] to promote GPCR association to clathrin-coated pits (CCPs). Deletion of the clathrin-binding site abrogates arrestin-promoted trafficking of the $\beta 2$-AR [14]. Additionally, $\beta$-arrestins interact with the clathrin adaptor complex AP-2 upon GPCR binding [14-16], to promote clathrin-coat assembly and receptor targeting to CCPs [17]. In addition to clathrin, $\beta$-arrestins also bind to other components of the endocytic machinery such as the $\mathrm{N}$-ethylmaleimide-sensitive fusion protein (NSF), the small G protein ARF6, and the phosphatidylinositol 4-phosphate 5 kinase PIP5 K I $\alpha$ [18-20].

2.3. Arrestins as Signaling Scaffolds. Besides their functions in GPCR desensitization and trafficking, $\beta$-arrestins are also capable of generating their own signals by scaffolding signaling molecules, such as non-receptor tyrosine kinases of the Src family, or MAP (mitogen-activated protein) kinases (ERK1/2, c-Jun N-terminal kinase 3 JNK3) (reviewed in [21]). $\beta$-arrestins therefore mediate a second wave of signaling distinct from G-protein-dependent signaling.

2.4. Arrestins and Ubiquitin. $\beta$-arrestins were also shown to regulate the final fate of the receptor, by acting on the balance between receptor recycling to the plasma membrane, or its lysosomal degradation. The posttranslational modification of plasma membrane proteins, including receptors, by ubiquitin is known to affect their sorting along the endocytic pathway $[22,23]$. $\beta$-arrestins have the ability to recruit ubiquitin ligases and promote receptor ubiquitylation, therefore acting as "adaptor" proteins [24]. Interestingly, a phylogenetic study has revealed that proteins of the arrestin family are present in all eukaryotes, except plants $[25,26]$. A body of evidence (detailed later in this review, [27]) indicates that these arrestin-related proteins are also involved in the regulation of plasma membrane proteins trafficking by acting as ubiquitin ligase adaptors. Therefore, this function seems to be one of the most conserved features within the arrestin family $[28,29]$.

Both arrestins and arrestin-related proteins are themselves targets of ubiquitylation. This was discovered very early on for $\beta$-Arr2 in response to agonist stimulation [30]. Likewise, the fungal arrestin-related protein PalF was shown to be ubiquitylated in response to alkaline ambient $\mathrm{pH}$, in a signal- and receptor- $(\mathrm{PalH})$ dependent manner [31]. This ubiquitylation appeared crucial for the proper function of arrestins [24, 32-35], but the precise role of this modification is poorly understood. An additional layer of complexity has recently been added following the observations that $\beta$-arrestins interact with deubiquitylating enzymes that regulate their ubiquitylation status as well as receptor ubiquitylation and, consequently, their fate [35-37].

In this review, we will focus on the connections between arrestins and ubiquitin. We will detail the function of arrestins and arrestin-related proteins as ubiquitin ligase adaptor and discuss how arrestin functions could be regulated by ubiquitylation.

\section{Arrestins as Ubiquitin Ligase Adaptors}

3.1. Ubiquitin and Endocytic Protein Sorting. Studies in the last decades have shown that ubiquitin is a master regulator of endocytosis in eukaryotes. Early work performed in the yeast Saccharomyces cerevisiae demonstrated that ubiquitin is involved in the endocytosis of plasma membrane proteins, such as ABC (ATP-binding cassette) transporters [38], receptor[39, 40], or permeases [41]. The ubiquitylation of plasma membrane proteins appears to trigger their internalization and targeting to endosomes [42], although the existence of an ubiquitin-independent internalization mechanism is also documented [43]. In mammalian cells, the situation is more complex, as several internalization pathways exist in the cell with only some of them regulated by ubiquitin [44].

Initially, it has been proposed that ubiquitylated cargoes are recognized in yeast and mammals by the ubiquitinbinding motifs of various proteins involved in endocytosis, such as Eps15 (Ede1 in yeast) and Epsin (Eps15 interacting; Ent1 and Ent2 in yeast) which display UIM (ubiquitininteracting motif) or UBA (ubiquitin-associated) domains $[45,46]$. In addition, these endocytic proteins can also interact with phosphoinositides and clathrin, making them ideal candidates to coordinate ubiquitin recognition and cargo internalization. While such a function appears to be established in mammalian cells [47-49], recent data in yeast favor a more complex model, where ubiquitinbinding domains would play a more general role in protein interactions and the assembly of the endocytic network [50]. Noteworthy, in mammalian cells, endocytic adaptors are often ubiquitylated in response to extracellular stimuli, and this contributes greatly to the ubiquitin-based signaling triggered upon cell stimulation [23, 51-53].

A second major ubiquitin-dependent step in the endocytic pathway occurs at multivesicular bodies (MVBs) and is required for cargo delivery into lysosomes [54]. Cargo 
ubiquitylation provides the crucial signal for entering into this pathway. A series of protein complexes, collectively named ESCRT (endosomal sorting complex required for transport) carry ubiquitin-binding domains and act in concert to allow the recognition and sorting of ubiquitylated cargoes into luminal vesicles of MVBs [55]. Therefore, lack of cargo ubiquitylation at this stage leads to a defective targeting to the lysosome, and, eventually, recycling [56].

In mammalian cells, initial studies showed that the ubiquitin conjugation system is important for the downregulation of the growth hormone receptor (GHR) [57]. Also, the study of the amiloride-sensitive epithelial sodium channel $\mathrm{ENaC}$ clearly established that its ubiquitylation regulates the channel's stability [58]. Subsequent work on ENaC, GHR, and many other receptors (such as EGFR, PDGFR, c-Met, TGF- $\beta R, \beta 2-A R$ ) confirmed the critical function of ubiquitin in endocytosis in mammals $[23,59,60]$. However, where this ubiquitylation occurs in the cell (plasma membrane or endosomal compartments), and how ubiquitylation impacts on the target receptor's fate (internalization, progression through the endocytic pathway, or degradation) are still a matter of debate and seem to vary upon the receptor and the physiological situation considered [61]. Also, it should be noted that while ubiquitin-mediated endocytosis appears as the main pathway in yeast, ubiquitin-independent endocytosis is more represented in higher eukaryotes [44, $62]$.

3.2. The "Classic" $\beta$-Arr2/ $\beta 2$-AR Couple. A first evidence for the role of arrestins in receptor ubiquitylation came from a study by Shenoy and colleagues who observed that the $\beta 2$-AR is ubiquitylated within $15 \mathrm{~min}$ of isoproterenol stimulation, ultimately leading to receptor degradation [30]. $\beta 2$-AR ubiquitylation requires $\beta$-Arr2 and the ubiquitin ligase MDM2, which turned out to ubiquitylate $\beta$-Arr2 rather than $\beta 2$-AR (see below) [30]. A mutant $\beta 2$-AR lacking the ubiquitylation sites $\left(\beta 2-A R^{\mathrm{K} 0}\right)$ is normally internalized, but not degraded [30]. In contrast, a translational fusion of ubiquitin to the $\beta 2-\mathrm{AR}$, which mimics its constitutive ubiquitylation, is internalized similarly as the wild-type $\beta 2$ AR, but is degraded more efficiently [24].

Therefore, ubiquitylation is a critical signal for $\beta 2$ AR degradation upon stimulation. A similar implication of GPCR ubiquitylation in its degradation, but not in its internalization, was also reported in the case of CXCR4 [63]. The identity of the ubiquitin ligase responsible for $\beta 2$-AR ubiquitylation was revealed more recently. Indeed, $\beta$-Arr2 was found to interact with the HECT-type (homologous to E6-AP C-terminus) ubiquitin ligase Nedd4 (discussed below in this paper). Nedd4 (neural precursor cell expressed developmentally downregulated protein 4 ) promotes $\beta 2$ AR ubiquitylation at endosomes, leading to its lysosomal targeting [24].

Once internalized, GPCRs can also escape degradation and recycle back to the plasma membrane in a functional state to mediate further signaling. Because GPCR ubiquitylation appears to trigger its degradation, deubiquitylation could regulate GPCR recycling to the plasma membrane.
Indeed, two deubiquitylating enzymes named USP33 and USP20 regulate $\beta 2$-AR deubiquitylation, recycling and resensitization [35, 37]. USP33 was first identified as a $\beta$-arrestin interactant, thus suggesting that $\beta$-Arr2 could be involved in USP33 recruitment to $\beta 2$-AR [35]. However, USP33 was found to interact with $\beta 2$-AR even before agonist stimulation, that is, when $\beta$-Arr2 is not yet translocated to the plasma membrane [37]. In fact, USP33 appears to be transferred from agonist-activated $\beta 2$-AR to $\beta$-Arr2, thus triggering its deubiquitylation and dissociation from the receptor, once internalized. Reassociation of USP33 with $\beta 2$-AR in endosomal compartments would regulate its deubiquitylation and recycling to the plasma membrane. Thus, the association and dissociation of $\beta$-Arr2 from $\beta 2$ AR may coordinate the ubiquitin conjugating/deconjugating activities towards $\beta 2$-AR to tune the balance between receptor degradation and recycling. This positions the ubiquitin ligase adaptor function of $\beta$-Arr2 as a key regulator of GPCR signaling.

\section{3. $\beta$-Arrestins as Ubiquitin Ligase Adaptors: Other Examples.} The function of $\beta$-arrestins as ubiquitin ligase adaptors is not restricted to $\beta 2$-AR. Additional studies identified $\beta$ arrestins as ubiquitin ligase adaptors for non-GPCR proteins: $\beta$-Arr1, as $\beta$-Arr2, acts as an adaptor for ubiquitin ligases of the Nedd4 family such as Itch/AIP4 (Atrophin-1-interacting protein 4) for ubiquitylation of the TRPV4 (transient receptor potential) channel [64], and Nedd4 for that of the $\mathrm{Na}^{+} / \mathrm{H}^{+}$exchanger 1 (NHE1) [65]. In the latter case, however, and in contrast to the situation described for the $\beta 2$ $\mathrm{AR}$, cargo ubiquitylation is required for its internalization. Because $\beta$-arrestins interact with both ubiquitin ligase and clathrin (see above), they may then act at two levels: first, for cargo ubiquitylation, which could recruit Eps15/Epsin endocytic adaptors, and, second, to assist the latter in the recruitment of a clathrin coat.

The contribution of $\beta$-arrestins to the trafficking of another classical GPCR, the chemokine receptor, CXCR4, was also studied. Early reports had shown that the ligandinduced ubiquitylation of CXCR4 by the Nedd4-like ubiquitin ligase AIP4 is required for its lysosomal sorting $[63,66]$. $\beta$-Arr1 interacts with AIP4 at endosomes, and knockdown experiments revealed that $\beta$-Arr1 is an important player in CXCR4 degradation but, surprisingly, is not required for its ubiquitylation [67]. Instead, CXCR4 is phosphorylated at the plasma membrane after ligand binding, which allows the direct recruitment of the ubiquitin ligase AIP4 via its WW domains, and hence CXCR4 ubiquitylation [68]. $\beta$ Arr1 was later found to interact with the ESCRT-0 complex and to direct the ubiquitylation of one of its components, HRS (hepatocyte growth factor-regulated tyrosine kinase substrate) in a CXCR4-dependent manner [69].

Interestingly, $\beta$-arrestins appear to act primarily as adaptors for ubiquitin ligase of the Nedd 4 family. These enzymes display WW domains that can interact with specific proline-rich motifs (usually, a $[\mathrm{L} / \mathrm{P}] \mathrm{PxY}$ sequence). Although this motif is sometimes present on the targeted substrates, as in the case of $\mathrm{ENaC}[70]$, in most cases this interaction 
motif is present on an adaptor protein in charge of substrate recognition [71]. However, no $\mathrm{PPxY}$ motif has been found in $\beta$-arrestins, and polyproline regions are not involved in Nedd4 interaction [24]. In addition, Nedd4 recruitment to $\beta 2$-AR was not affected by mutations in Nedd4 WW domains. This indicates that this interaction involves a noncanonical binding of $\beta$-Arr2 to Nedd4, for which the molecular determinants remain to be addressed.

In some cases, $\beta$-arrestins act as adaptors for ubiquitin ligase which do not belong to the Nedd4 family. $\beta$-Arr 1 was proposed to act as an adaptor for the RING (Really interesting new gene) ubiquitin ligase $\mathrm{Mdm} 2$ to mediate insulin-like growth factor I (IGF-1) receptor ubiquitylation and downregulation $[72,73]$. A similar role was appointed to $\beta$-Arr2 for the ubiquitylation of the androgen receptor [74]. Again, the molecular basis of this interaction awaits further investigations.

\section{Arrestin-Related Proteins: New Players in the Field}

Visual and $\beta$-arrestins share a similar structure, with an arrestin fold in their $\mathrm{N}$-terminal domains and a $\mathrm{C}$-terminal tail [75-80]. It was proposed that visual and $\beta$-arrestins actually originate from an ancestral arrestin family from which they diverged relatively recently [25]. This ancestral family would also have given rise to proteins whose expression is not limited to metazoans: members of the Vps26 family, which display an arrestin-like fold [81, 82], as well as arrestin-related proteins (also coined $\alpha$-arrestins) [25]. Indeed, proteins displaying sequence homologies to arrestins were first identified in the filamentous fungus Aspergillus nidulans, named CreD [83] and PalF [31], and more recent work in yeast allowed to identify additional members of this protein family renamed "ART" (arrestinrelated trafficking adaptors) $[34,84,85]$ that will be discussed later in this paper. In human, the ART family is composed of six members, named arrestin-domain containing 1-5 (ARRDC1-5) and TXNIP (Thioredoxin-interacting protein) (Figure 1). Therefore, arrestin-related proteins are expressed in all eukaryotes, except plants, which interestingly do not harbor Nedd4-like genes either [25].

4.1. Arrestin-Related Proteins as Endocytic Adaptors. A main difference between visual $/ \beta$-arrestins and arrestin-related proteins is that the latter possess PPxY motifs (Figure 1). In agreement with the reported function of these motifs (see above), many studies have documented the ability of yeast arrestin-related proteins to interact with the only Nedd4-like ubiquitin ligase in S. cerevisiae, named Rsp5 [33, 34, 85-90]. Rsp5 is critical for ubiquitin-dependent intracellular trafficking pathways, such as endocytosis and MVB sorting [91]. However, most of the transporters lack PPxY motifs, and until recently, the molecular basis for the interaction between Rsp5 and transporters was unknown. It has become clear that yeast arrestin-related proteins fulfill this function, by acting as Rsp5 adaptors to mediate ubiquitylation and subsequent endocytosis of transporters
[33, 34, 84, 85, 90]. Using a chemical-genetic screen, Emr and colleagues have identified Ldb19/Art1 as a regulator of the endocytosis of Can1, an arginine transporter [34]. The function of Ldb19/Art1 was also extended to the endocytosis of other amino acid transporters. In a parallel study, Nikko et al. showed that two other arrestin-related proteins, named Ecm21/Art2 and Csr2/Art8, are specifically involved in the downregulation of the manganese transporter Smf1 [85]. Altogether, around 10 arrestin-related proteins were identified in yeast $[34,84,85]$, and gathered in a family referred to as "ART" (arrestin-related trafficking adaptors).

Contrary to the situation in mammalian cells, where $\beta$ arrestins mainly act at a late step in cargo sorting, studies in yeast suggested a role for arrestin-related proteins in cargo internalization at the plasma membrane [27]. Indeed, several yeast ARTs are involved in the signal-induced internalization of transporters in response to specific environmental signals $[33,34,84,85,90]$. In addition, Art1 relocalizes to the plasma membrane in response to the signal that induces amino acid transporter endocytosis $[34,92]$.

However, as for $\beta$-arrestins, the situation is probably more complex, and the role of ARTs in endocytosis may not be restricted to the plasma membrane. In the course of their study of the high-affinity iron-uptake protein complex Fet3/Ftr1 in yeast, Burd and colleagues documented an example of ubiquitin-independent internalization [43]. The results show that a nonubiquitylatable form of Fet3/Ftr1 can still be internalized but is constitutively recycled back to the plasma membrane, leading to an apparent defect in internalization. Although the involvement of an arrestin remains to be determined, it strongly suggests that in this system, cargo ubiquitylation by Rsp5 is required at endosomal compartments, rather than at the plasma membrane. In addition, two yeast arrestin-related proteins, Aly1/Art6 and Aly2/Art3, have been shown to localize to intracellular compartments and to control the trafficking of the general amino-acids transporter Gap1 between trans-Golgi and endosomes [93]. Consistent with these findings, Aly1 and Aly2 interact with both clathrin and Golgi-specific clathrin adaptor complex AP-1, thus suggesting that arrestin related proteins, as $\beta$-arrestins, promote clathrin-coat assembly and cargo targeting to clathrin-coated vesicles. Therefore, futures studies will be necessary to precise where yeast arrestinrelated proteins act on cargo trafficking. Regarding their intracellular localizations, we can already hypothesize several modes of action within the ART family of proteins.

Like their yeast homologs, several human ARRDC proteins are able to interact with ubiquitin ligases of the Nedd4 family [94-97]. Among those, ARRDC3 was isolated in a screen designed to identify proteins involved in $\beta 2$-AR ubiquitylation and degradation after agonist treatment [95]. ARRDC3, as $\beta$-Arr2 [24], was shown to bridge the interaction between Nedd4 and $\beta 2-A R$, leading to the intriguing possibility that arrestin-related proteins might coordinate, together with $\beta$-arrestins, receptor ubiquitylation and degradation. Because both classes of arrestins have the ability to dimerize $[94,98]$, this raises the possibility of potential heterooligomers between arrestin and arrestin-related proteins that 
Human

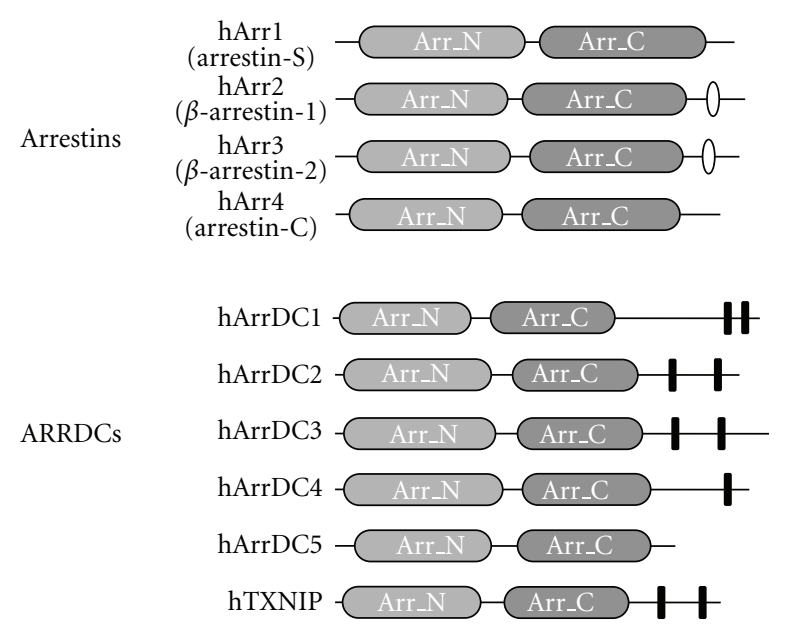

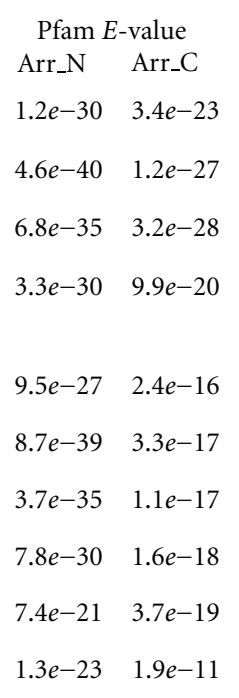

Pfam E-value

$1.2 e-30 \quad 3.4 e-23$

$4.6 e-40 \quad 1.2 e-27$

$6.8 e-35 \quad 3.2 e-28$

$3.3 e-30 \quad 9.9 e-20$

$9.5 e-27 \quad 2.4 e-16$

$8.7 e-39 \quad 3.3 e-17$

$3.7 e-35 \quad 1.1 e-17$

$7.4 e-21 \quad 3.7 e-19$

$1.3 e-23 \quad 1.9 e-11$

S. cerevisiae

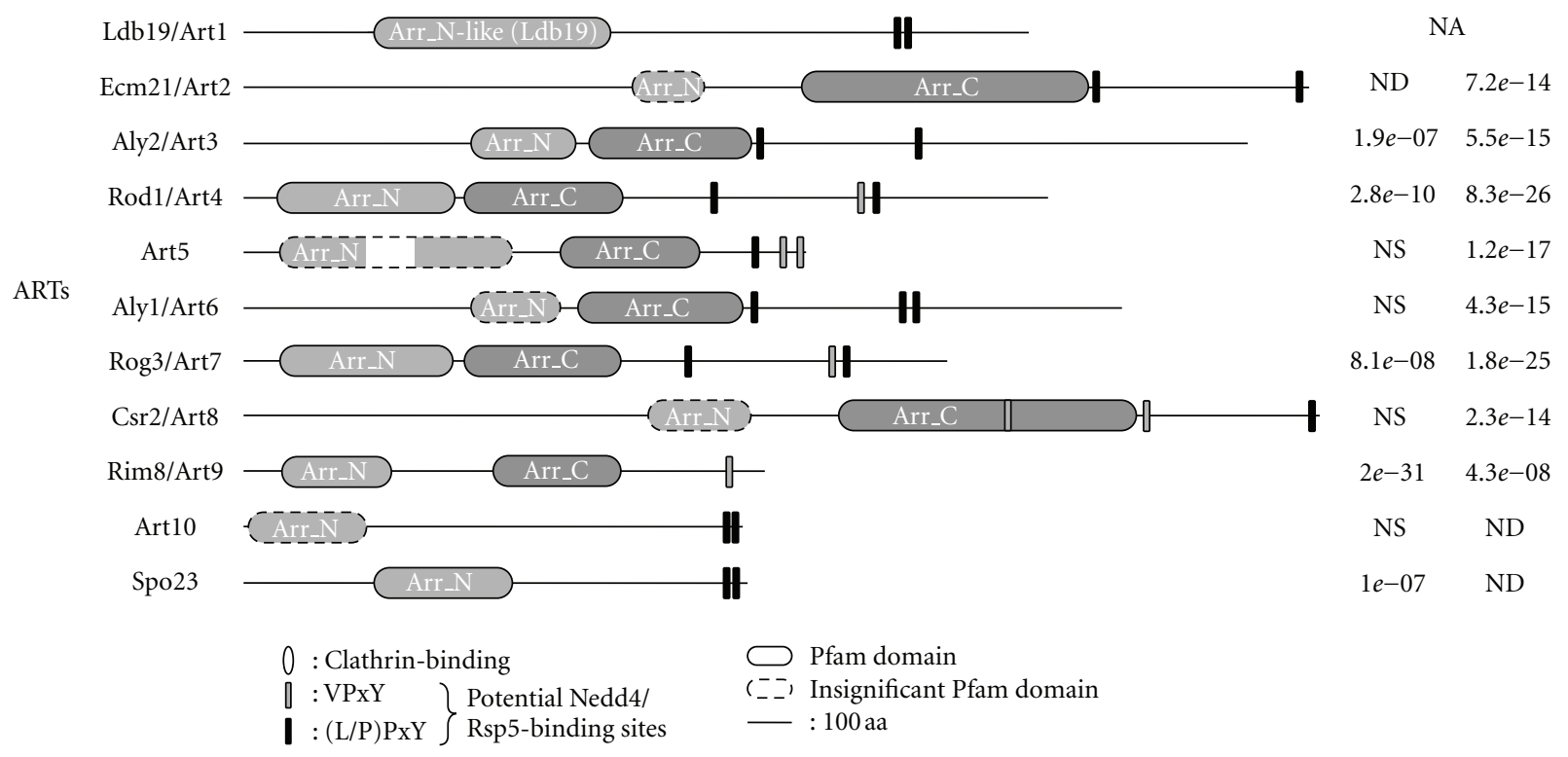

FIGURE 1: Schematic representation of the domain organization of human arrestins and arrestin-domain containing (ARRDC) proteins, and yeast ARTs (arrestin-related trafficking adaptors). Domains detected by Pfam 26.0 (http://pfam.sanger.ac.uk/) are shown and correspond to the following Pfam-A accessions: Arr_N: PF00339, Arr_C: PF02752, Arr_N-like (Ldb19): PF13002, along with the corresponding E-values for each domain (NA: not applicable; ND: not detected; NS: not significant). A putative Arr_N domain in Ecm21/Art2 was identified by alignment with the presumed Arr_N domain of Csr2/Art8. Clathrin-binding sites are depicted on $\beta$-arrestins; potential binding sites for ubiquitin ligases of the Nedd 4 family are also indicated on arrestin-related proteins.

could reveal a complementary role between arrestin classes.

The basic function of arrestin-related proteins as ubiquitin ligase adaptor therefore seems strongly conserved. Of note, a role for ARRDC3 in the degradation of a cell surface adhesion molecule, integrin $\beta 4$, was also pointed out, but its role as ubiquitin ligase adaptor in this context has not been investigated [99]. Future studies will indubitably unravel new connections between ubiquitin and arrestin-related proteins.
4.2. Other Functions of Arrestin-Related Proteins: An ESCRT Connection. As previously mentioned, arrestin-related proteins were initially identified in A. nidulans and named CreD [83] and PalF [31]. Interestingly, in both cases, a connection with the ubiquitin pathway was established. CreD was shown to interact physically with the Nedd4 homologue in A. nidulans, HulA, whereas PalF was found to be ubiquitylated in vivo. PalF, a protein involved in the ambient $\mathrm{pH}$ signaling in fungi, binds to the seven-transmembrane and putative 
$\mathrm{pH}$ sensor, PalH. This pointed out to many similarities between mammalian $\beta$-arrestins and this arrestin-related protein [31].

As in A. nidulans, the yeast PalF homologue Rim8/Art9 is essential for the proteolytic activation of the $\mathrm{pH}$-responsive transcription factor, Rim101, in response to neutral-alkaline $\mathrm{pH}$ [100]. Interestingly, there is an intricate connection between the ESCRT machinery, involved in ubiquitindependent cargo sorting at the MVB, and this signaling pathway [100-102]. The ART Rim8/Art9 is central to the coordination of the ESCRT machinery and the $\mathrm{pH}$ signaling pathway, as it interacts with both the putative $\mathrm{pH}$ sensor Rim21 and the ESCRT-I subunit Vps23 [89]. ESCRT appears to provide a platform for recruitment of a protein complex containing the ESCRT-III binding protein and ALIX homologue Rim20, that enables the proteolytic activation of the Rim101 transcription factor in response to the $\mathrm{pH}$ signal. Although initial studies suggested that this process takes place at the endosomal membrane [103], subsequent work supported the idea that arrestin-mediated recruitment of ESCRT in the fungal ambient $\mathrm{pH}$ signaling pathway may occur at the plasma membrane $[89,104]$. Similarly, some of the human ARRDCs interact with the Vps23 homologue TSG101 or the ESCRT-associated protein ALIX [90, 96]. In particular, ARRDC1-mediated recruitment of ESCRT appears to drive the formation of microvesicles at the plasma membrane that may be involved in intercellular communication [94, 105]. Interestingly, this situation is reminiscent of the budding step of different enveloped RNA viruses, which recruit ESCRT components through similar interactions to promote membrane scission and subsequent viral particle release [106]. Accordingly, overexpression of several ARRDCs inhibits murine leukemia virus (MLV) viral particle release in a PPxY-specific way [96]. Therefore, ARRDCs may act as adaptors between Nedd4-like enzymes and the ESCRT machinery, in viral budding.

Finally, the connection between arrestin and the ESCRT machinery may not be restricted to arrestin-related proteins. Indeed, and as previously mentioned, $\beta$-Arr 1 was found to interact with STAM-1 (signal-transducing adaptor molecule), a component of ESCRT-0, to regulate endosomal sorting of CXCR4 [69].

\section{Regulation of Arrestin Function by Ubiquitin}

5.1. Regulation of $\beta$-Arrestins by Ubiquitylation. Arrestins are specifically recruited to the cargoes following agonist stimulation (receptor) or in response to the presence of the substrate (transporter, channel), thus suggesting that they are regulated to mediate an adapted response of the cell to extracellular changes.

As mentioned previously, Shenoy and colleagues showed in a seminal article that $\beta$-Arr2 is itself ubiquitylated in response to agonist treatment [30]. Ubiquitylation of $\beta$ Arr2, in contrast to that of $\beta 2$-AR, does not require Nedd4, but an ubiquitin ligase of the RING family, Mdm2. As this modification occurred upon stimulation, this suggested a role for $\beta$-Arr2 ubiquitylation in $\beta$-AR trafficking. Indeed,
Mdm2 knockdown caused a defect in $\beta 2$-AR internalization. Thus, $\beta$-Arr2 ubiquitylation appears to play a key role in GPCR trafficking, and several lines of evidences support this idea.

To address directly the importance of this posttranslational modification and to avoid potential indirect effects of the knockdown of the $\mathrm{Mdm} 2$ ubiquitin ligase on $\beta 2$-AR trafficking, studies were performed using both a nonubiquitylatable mutant form of $\beta$-Arr2 $\left(\beta-\operatorname{Arr} 2^{0 \mathrm{~K}}\right)$ and a translational fusion of ubiquitin to $\beta$-Arr2 $(\beta$-Arr2Ub) [107]. These experiments showed that $\beta-A r r 2^{0 \mathrm{~K}}$ recruitment to the plasma membrane was only transient and unable to trigger internalization of $\beta 2$-AR. On the opposite, translational fusion of ubiquitin to $\beta$-Arr2 led to its co-trafficking with $\beta 2$-AR into endosomal compartments [107]. Previous observations had classified GPCRs in two classes (A and $\mathrm{B}$ ), based on the interaction pattern between receptor and $\beta$-arrestin. Interaction of $\beta$-arrestin with class A receptors (e.g., $\beta 2$-AR) only takes place at the plasma membrane, while its interaction with class $B$ receptors (e.g., angiotensin II type 1a receptor: AT1aR, or vasopressin V2 receptor: $\mathrm{V} 2 \mathrm{R}$ ) is more stable and persists even after receptor internalization [108]. Interestingly, the increased stability of the interaction between class $\mathrm{B}$ receptors and $\beta$-arrestin correlates with a sustained $\beta$-arrestin ubiquitylation, which is not observed with class A receptors [36]. Indeed, even if $\beta-A r r 2^{\mathrm{K} 0}$ is able to interact with the receptor in vitro, this interaction is weaker than that displayed with the wild type form in vivo. On the opposite, translational fusion of ubiquitin to $\beta$-Arr2 displays a stronger binding than wild type $\beta$-Arr2 [107]. $\beta$-Arr2 ubiquitylation therefore appears to reinforce the interaction with $\beta 2$-AR.

Because $\beta$-Arr2 is capable of interacting with the endocytic machinery, such as clathrin or clathrin adaptors, the failure of $\beta-A r r 2^{\mathrm{K} 0}$ to promote $\beta 2$-AR internalization could originate from an impaired interaction with these components. Indeed, $\beta-A r r{ }^{\mathrm{K} 0}$ exhibits a weaker interaction with clathrin than the wild-type form [107]. While clathrin is not known to interact with ubiquitin, $\beta$-Arr2 ubiquitylation might stabilize the interaction with clathrin through other components of the endocytic machinery such as Eps15/epsin proteins that are able to bind both ubiquitin and clathrin.

$\beta$-Arr2 ubiquitylation was also shown to affect its scaffolding function for signaling proteins. The amplitude of $\beta$-arrestin-mediated activation of ERK (extracellular signalregulated kinase) correlates with the $\beta$-Arr2 ubiquitylation status. Although $\beta$-Arr2 ubiquitylation was not required for its interaction with MAP kinases (such as c-Raf and ERK), translational fusion of ubiquitin to $\beta$-Arr2 led to an increased level of ERK activity in endosome localized receptor complexes (signalosomes). Consistent with these findings, $\beta$-arrestin ubiquitylation promote its association with membrane. Again, ubiquitylation appears to function in stabilizing the $\beta$-arrestin-mediated interaction between the receptor and signaling proteins [107].

Finally, arrestins undergo conformational changes upon binding to activated receptors [109]. Ubiquitin modification 
could therefore contribute to the proper rearrangement of the $\beta$-arrestin structure, leading to optimal interactions with its partners, and this awaits further investigations.

\subsection{Regulation of Arrestin-Related Protein by Ubiquitylation.} Many arrestin-related proteins have also been reported as substrates for ubiquitylation, both in fungi and human $[31,33,34,89,90,94,96,97,110]$. Ubiquitylation of these proteins, in contrast to that of $\beta$-arrestins, is triggered by ubiquitin ligases of the Nedd 4 family. Therefore, arrestinrelated proteins are adaptors as well as targets of the same ubiquitin ligases.

The yeast arrestin-related protein Ldb19/Art1 is required for the endocytosis of amino acid permeases, such as the arginine transporter, Can1. Failure to endocytose Can1 leads to sensitivity of the cells to canavanine, a toxic analog of arginine. A nonubiquitylatable mutant of Ldb19/Art1 cannot grow on this drug, suggesting that Can 1 remains at the plasma and therefore that Art1 is not functional [34]. The importance of ubiquitylation for ART function was also demonstrated for Rod1/Art4, involved in the glucoseinduced endocytosis of carbon sources transporters [33, 84]. Rod1/Art4 is ubiquitylated in response to glucose exposure and a nonubiquitylatable mutant is unable to promote the endocytosis of the lactate transporter, Jen1, following glucose treatment [33]. Altogether, these data indicate that ART ubiquitylation is crucial for their function in endocytosis. Human arrestin-related protein ARRDC3 was isolated in a screen designed to identify genes involved in $\beta 2$-AR degradation, and acts as a Nedd 4 adaptor for $\beta 2$ AR ubiquitylation [95]. While ARRDC3 ubiquitylation has not yet been observed, ARRDC1 and TXNIP were shown to be ubiquitylated by ubiquitin ligases of the Nedd4 family $[90,96,97]$. Thus, it is tempting to speculate that the same regulation applies in fungi and human.

The ubiquitylation of the arrestin-related protein PalF in A. nidulans is triggered in a signal-(alkaline $\mathrm{pH}$ ) and receptor-(PalH) dependent manner [31]. PalF ubiquitylation appears as a major determinant of its activity, since the translational fusion of ubiquitin to PalF leads to a constitutive activation of the pathway [110]. The yeast PalF homologue Rim8/Art9 was shown to be monoubiquitylated [89]. Monoubiquitylation of Rim8/Art9 occurs on a lysine residue in its $\mathrm{C}$-terminus and, as for all other ARTs described to date in yeast, is performed by Rsp5, which binds to a PxY motif near the ubiquitylation site. This monoubiquitylated residue, together with a SxP motif, contributes to the interaction of Rim8/Art9 with the ESCRT-I subunit Vps23 via its ubiquitin-binding domain, UEV (ubiquitin E2 variant) [89]. Interestingly, Vps23 binding appears to control the levels of monoubiquitylated Rim8/Art9, thus suggesting that this interaction either promotes Rim8 ubiquitylation or prevents its further polyubiquitylation and possibly its degradation. Interaction of human ARRDC1 with the Vps 23 homologue Tsg101 was shown to be mediated by a PSAP motif which, like the SxP motif in Rim8, is located at the protein Cterminus $[94,96]$. In addition, it was proposed that the ubiquitylation of ARRDC1 is important for its function [94].
However, this is based on results obtained upon depletion of the corresponding Nedd4-like ligase WWP1, which in principle could also impair a potential adaptor function and may have off-target effects. Therefore, the identification and mutation of the ubiquitylation sites will be critical to address this question.

\subsection{Dynamic Regulation of Arrestin Ubiquitylation. Phosphorylation-Dependent Ubiquitylation? Because} ubiquitin ligases target a large number of proteins in the cell, their activity toward a given substrate is usually indirectly regulated through substrate accessibility, either by the use of adaptor proteins, or by post-translational modification of the substrate, such as phosphorylation [111].

Interestingly, cytosolic $\beta$-arrestins are constitutively phosphorylated, and undergo dephosphorylation upon binding to the activated receptor. $\beta$-Arr1 dephosphorylation is required for $\beta 2$-AR internalization, but not for its desensitization [112]. Indeed, a $\beta$-Arr1 mutant mimicking constitutive phosphorylation displays a weaker interaction with clathrin but an unaltered $\beta 2$-AR binding [112]. Similar data were reported for $\beta$-Arr2, and the phosphorylation site was localized near the clathrin and AP-2 binding motifs, thus providing an explanation as to why $\beta$-Arr2 phosphorylation regulates the interaction with clathrin/AP-2 [113]. Additionally, the phosphorylation of the major visual arrestin in Drosophila (Arr2) also regulates its interaction with clathrin [114].

Importantly, once the receptor is internalized, $\beta$ Arr1 is rephosphorylated. These dynamic phosphorylation/dephosphorylation events suggest the involvement of kinases and phosphatases whose activation is coordinated in response to agonist exposure. Interestingly, $\beta$-Arr 1 is phosphorylated in vitro by ERK kinases and accordingly, the modulation of ERK activity in vivo affects $\beta$-Arr1 phosphorylation, thus providing an inhibitory feedback control of its function [115].

Although $\beta$-arrestins are both dephosphorylated and ubiquitylated upon receptor binding, an eventual relationship between these two modifications remained to be addressed. Such a link has been described for the yeast arrestin-related protein Rod1/Art4, involved in the glucoseinduced endocytosis of carbon sources transporters [33]. As for $\beta$-arrestins, Rod1/Art 4 dephosphorylation and ubiquitylation occurs in response to an external signal-in this case, glucose. The yeast homologue of AMPK (5'-AMP-activated protein kinase), Snf1, and its counteracting phosphatase PP1 (protein phosphatase 1) control the phosphorylation status of Art4/Rod1 in response to glucose availability. Therefore, in the absence of glucose, Art4/Rod1 is phosphorylated and endocytosis is inhibited. This inhibitory effect results from the ability of phosphorylated Art4/Rod1 to bind 14-3-3 proteins, thereby hindering its ubiquitylation by Rsp5 and hence preventing its activation [33].

Interestingly, phosphorylation of another yeast arrestinrelated protein, Ldb19/Art1, also regulates its function. A recent study indicated that Ldb19/Artl is subject to 
phosphoinhibition through the action of the TOR (target of rapamycin) effector and protein kinase $\mathrm{Npr}$, thus allowing cells to regulate amino acid transporter endocytosis in response to the nitrogen status [92]. While the overall phospho-inhibition mechanism recalls that of Rod1/Art4, Ldb19/Art1 ubiquitylation is uncoupled from its phosphorylation, suggesting a different regulatory mechanism [34]. The identification of Npr1-dependent phosphorylation sites on Ldb19/Art1 allowed generating a nonphosphorylatable mutant form of the protein. Interestingly, this mutant fails to be translocated at the plasma membrane upon stimulation, which likely explains why transporters endocytosis is impaired [92]. Further work will be needed to understand the molecular mechanism of this phosphorylationdependent inhibition.

Other examples of arrestin-related proteins that are subjected to phosphorylation which include A. nidulans PalF, involved in ambient $\mathrm{pH}$ sensing, although the regulatory mechanism appears to be different since PalF undergoes phosphorylation instead of dephosphorylation, in response to the ambient $\mathrm{pH}$ signal [31]. The same result has been observed in the pathogenic yeast Candida albicans, where the PalF homologue Rim8 is also phosphorylated in response to neutral-alkaline $\mathrm{pH}$ [116]. Although phosphorylation of Rim8/Art9 in baker's yeast has not been reported, its ubiquitylation does not appear to be regulated by ambient $\mathrm{pH}$, in contrast to that of PalF, which is induced by alkaline $\mathrm{pH}$ [89]. The apparent lack of regulation of Rim8/Art9 ubiquitylation is consistent with its role in Vps23 binding, which appears to occur even in nonstimulated conditions. Thus, the $\mathrm{pH}$-dependent regulation of PalF ubiquitylation in $A$. nidulans may reflect an additional level of regulation in this organism.

From these studies, it emerges that arrestin-related proteins are often modified posttranslationally in response to stimulation, either by phosphorylation, ubiquitylation, or both. A crosstalk between phosphorylation and ubiquitylation has been evidenced. How these modifications operate to coordinate arrestin function is unknown, and this provides new avenues for research in this field.

Ubiquitylation and deubiquitylation. Ubiquitylation, akin to phosphorylation, is a reversible process. Therefore, deubiquitylation appeared as a possible mechanism for regulation of arrestin function. In support of this idea, the transient $\beta$-Arr2 ubiquitylation associated to class A receptor suggested that deubiquitylation occurs rapidly after agonist stimulation. Indeed, the ubiquitin-specific protease 33 (USP33) was shown to deubiquitylate $\beta$-Arr2 following $\beta 2$-AR binding [35]. USP33 knock-down led to an increase in $\beta$-Arr2 ubiquitylation. This was accompanied by a stronger interaction with the receptor, and a prolonged $\beta$-Arr2-dependent MAP kinase signaling. These findings are consistent with the phenotypes of cells expressing a translational fusion of ubiquitin to $\beta$-Arr2 (see above) and provide an additional mechanism for the regulation of arrestin function. Strikingly, recruitment of USP33 to $\beta$-Arr2 depends on the receptor class, in agreement with previous finding that receptor class determines the kinetics of $\beta$-Arr2 deubiquitylation [36]. In addition, receptors belonging to the same class can target different lysine residues on $\beta$-Arr2 for ubiquitylation [32]. Therefore, binding of $\beta$-Arr2 to different receptors may trigger distinct conformational change that could modulate both ubiquitylation sites accessibility and association with deubiquitylating enzymes, hence leading to a different functional output-in full support of the concept of an "ubiquitylation code."

\section{Concluding Remarks}

In this paper, we emphasized the many relationships between ubiquitin metabolism and arrestin biology. Many proteins of the arrestin family act as ubiquitin ligase adaptors and are required for ubiquitylation of endocytic cargo. In particular, recent data obtained on arrestin-related proteins have pointed out several features shared with $\beta$-arrestins, such as the intimate connection existing between these proteins and ubiquitin ligases of the Nedd4 family. In addition, ubiquitin also regulates arrestin function in a yet undefined way, which is now critical to understand. However, the emergence of new regulatory mechanisms involving a now expanded family of arrestin proteins, combined with the multiplicity of model organisms, is likely to favor the rapid evolution of concepts in arrestin biology.

\section{Abbreviations}

$\begin{array}{ll}\text { AIP4: } & \text { Atrophin-interacting protein } 4 \\ \text { AP-1/AP-2: } & \text { Clathrin adaptor protein } \\ \text { ARRDC: } & \text { Arrestin-domain Containing } \\ \text { ART: } & \text { Arrestin-related trafficking adaptors } \\ \beta \text {-Arr: } & \beta \text {-arrestin } \\ \beta 2-A R: & \beta 2 \text {-adrenergic receptor } \\ \text { ERK: } & \text { Extracellular signal-regulated Kinase } \\ \text { ESCRT: } & \text { Endosomal sorting complex required for } \\ & \text { transport } \\ \text { GPCRS: } & \text { G-protein-coupled receptors. } \\ \text { MAP: } & \text { Mitogen-activated protein } \\ \text { MVBs: } & \text { Multivesicular bodies } \\ \text { Nedd4: } & \text { Neural precursor cell expressed } \\ & \text { developmentally downregulated protein } 4 \\ \text { RING: } & \text { Really interesting new gene } \\ \text { TXNIP: } & \text { Thioredoxin-interacting protein. }\end{array}$

\section{Acknowledgments}

This work was supported by the CNRS and by a Grant from the Fondation ARC pour la recherche sur le cancer (SFI20101201844) to S. Léon, and by a Grant from the Spanish CICYT (BFU2008-02005) to O. Vincent. M. Becuwe and A. Herrador are recipients of Ph.D. fellowships from the French Ministère de l'Enseignement Supérieur et de la Recherche and from CSIC-JAE, respectively.

\section{References}

[1] U. Wilden, S. W. Hall, and H. Kuhn, "Phosphodiesterase activation by photoexcited rhodopsin is quenched when rhodopsin is phosphorylated and binds the intrinsic $48-\mathrm{kDa}$ 
protein of rod outer segments," Proceedings of the National Academy of Sciences of the United States of America, vol. 83, no. 5, pp. 1174-1178, 1986.

[2] R. Zuckerman and J. E. Cheasty, "A $48 \mathrm{kDa}$ protein arrests cGMP phosphodiesterase activation in retinal rod disk membranes," FEBS Letters, vol. 207, no. 1, pp. 35-41, 1986.

[3] V. V. Gurevich, S. M. Hanson, X. Song, S. A. Vishnivetskiy, and E. V. Gurevich, "The functional cycle of visual arrestins in photoreceptor cells," Progress in Retinal and Eye Research, vol. 30, no. 6, pp. 405-430, 2011.

[4] J. L. Benovic, H. Kühn, I. Weyand, J. Codina, M. G. Caron, and R. J. Lefkowitz, "Functional desensitization of the isolated $\beta$-adrenergic receptor by the beta-adrenergic receptor kinase: potential role of an analog of the retinal protein arrestin (48-kDa protein)," Proceedings of the National Academy of Sciences of the United States of America, vol. 84, no. 24, pp. 8879-8882, 1987.

[5] M. J. Lohse, J. L. Benovic, J. Codina, M. G. Cargon, and R. J. Lefkowitz, " $\beta$-arrestin: a protein that regulates $\beta$-adrenergic receptor function," Science, vol. 248, no. 4962, pp. 1547-1550, 1990.

[6] H. Attramadal, J. L. Arriza, C. Aoki et al., " $\beta$-arrestin2, a novel member of the arrestin/ $\beta$-arrestin gene family," Journal of Biological Chemistry, vol. 267, no. 25, pp. 17882-17890, 1992.

[7] S. M. DeWire, S. Ahn, R. J. Lefkowitz, and S. K. Shenoy, “ $\beta$ arrestins and cell signaling," Annual Review of Physiology, vol. 69, pp. 483-510, 2007.

[8] V. V. Gurevich and E. V. Gurevich, "The molecular acrobatics of arrestin activation," Trends in Pharmacological Sciences, vol. 25, no. 2, pp. 105-111, 2004.

[9] A. C. Hanyaloglu and M. von Zastrow, "Regulation of GPCRs by endocytic membrane trafficking and its potential implications," Annual Review of Pharmacology and Toxicology, vol. 48, pp. 537-568, 2008.

[10] C. A. C. Moore, S. K. Milano, and J. L. Benovic, "Regulation of receptor trafficking by GRKs and arrestins," Annual Review of Physiology, vol. 69, pp. 451-482, 2007.

[11] J. G. Krupnick, O. B. Goodman Jr., J. H. Keen, and J. L. Benovic, "Arrestin/clathrin interaction. Localization of the clathrin binding domain of nonvisual arrestins to the carboxyl terminus," Journal of Biological Chemistry, vol. 272, no. 23, pp. 15011-15016, 1997.

[12] O. B. Goodman Jr., J. G. Krupnick, F. Santini et al., “ $\beta$ arrestin acts as a clathrin adaptor in endocytosis of the $\beta_{2}$ adrenergic receptor," Nature, vol. 383, no. 6599, pp. 447-450, 1996.

[13] O. B. Goodman Jr., J. G. Krupnick, V. V. Gurevich, J. L. Benovic, and J. H. Keen, "Arrestin/clathrin interaction. Localization of the arrestin binding locus to the clathrin terminal domain," Journal of Biological Chemistry, vol. 272, no. 23, pp. 15017-15022, 1997.

[14] Y. M. Kim and J. L. Benovic, "Differential roles of arrestin-2 interaction with clathrin and adaptor protein 2 in $\mathrm{G}$ proteincoupled receptor trafficking," Journal of Biological Chemistry, vol. 277, no. 34, pp. 30760-30768, 2002.

[15] S. A. Laporte, W. E. Miller, K. M. Kim, and M. G. Caron, " $\beta$-arrestin/AP-2 interaction in G protein-coupled receptor internalization. Identification of a $\beta$-arrestin binding site $\beta_{2}$ adaptin," Journal of Biological Chemistry, vol. 277, no. 11, pp. 9247-9254, 2002.

[16] S. A. Laporte, R. H. Oakley, J. Zhang et al., "The $\beta_{2}$ adrenergic receptor/ $\beta$ arrestin complex recruits the clathrin adaptor AP-2 during endocytosis," Proceedings of the National
Academy of Sciences of the United States of America, vol. 96, no. 7, pp. 3712-3717, 1999.

[17] M. A. Edeling, S. K. Mishra, P. A. Keyel et al., "Molecular switches involving the AP- $2 \beta_{2}$ appendage regulate endocytic cargo selection and clathrin coat assembly," Developmental Cell, vol. 10, no. 3, pp. 329-342, 2006.

[18] A. Claing, W. Chen, W. E. Miller et al., “ $\beta$-arrestin-mediated ADP-ribosylation factor 6 activation and $\beta_{2}$-Adrenergic receptor endocytosis," Journal of Biological Chemistry, vol. 276, no. 45, pp. 42509-42513, 2001.

[19] P. H. McDonald, N. L. Cote, F. T. Lin, R. T. Premont, J. A. Pitcher, and R. J. Lefkowitz, "Identification of NSF as a $\beta$-arrestin1-binding protein: implications for $\beta_{2}$-adrenergic receptor regulation," Journal of Biological Chemistry, vol. 274, no. 16, pp. 10677-10680, 1999.

[20] C. D. Nelson, J. J. Kovacs, K. N. Nobles, E. J. Whalen, and R. J. Lefkowitz, " $\beta$-arrestin scaffolding of phosphatidylinositol 4phosphate 5-kinase I $\alpha$ promotes agonist-stimulated sequestration of the $\beta_{2}$-adrenergic receptor," Journal of Biological Chemistry, vol. 283, no. 30, pp. 21093-21101, 2008.

[21] L. M. Luttrell and D. Gesty-Palmer, "Beyond desensitization: physiological relevance of arrestin-dependent signaling," Pharmacological Reviews, vol. 62, no. 2, pp. 305-330, 2010.

[22] F. Acconcia, S. Sigismund, and S. Polo, "Ubiquitin in trafficking: the network at work," Experimental Cell Research, vol. 315, no. 9, pp. 1610-1618, 2009.

[23] S. Polo, "Signaling-mediated control of ubiquitin ligases in endocytosis," BMC Biology, vol. 10, article 25, 2012.

[24] S. K. Shenoy, K. Xiao, V. Venkataramanan, P. M. Snyder, N. J. Freedman, and A. M. Weissman, "Nedd4 mediates agonistdependent ubiquitination, lysosomal targeting, and degradation of the $\beta_{2}$-adrenergic receptor," Journal of Biological Chemistry, vol. 283, no. 32, pp. 22166-22176, 2008.

[25] C. E. Alvarez, "On the origins of arrestin and rhodopsin," BMC Evolutionary Biology, vol. 8, no. 1, article 222, 2008.

[26] L. Aubry, D. Guetta, and G. Klein, "The arrestin fold: variations on a theme," Current Genomics, vol. 10, no. 2, pp. 133-142, 2009.

[27] S. Polo and P. P. di Fiore, "Finding the right partner: science or ART?” Cell, vol. 135, no. 4, pp. 590-592, 2008.

[28] A. K. Shukla, K. Xiao, and R. J. Lefkowitz, "Emerging paradigms of $\beta$-arrestin-dependent seven transmembrane receptor signaling," Trends in Biochemical Sciences, vol. 36, no. 9, pp. 457-469, 2011.

[29] S. K. Shenoy and R. J. Lefkowitz, " $\beta$-arrestin-mediated receptor trafficking and signal transduction," Trends in Pharmacological Sciences, vol. 32, no. 9, pp. 521-533, 2011.

[30] S. K. Shenoy, P. H. McDonald, T. A. Kohout, and R. J. Lefkowitz, "Regulation of receptor fate by ubiquitination of activated $\beta_{2}$-adrenergic receptor and $\beta$-arrestin," Science, vol. 294, no. 5545, pp. 1307-1313, 2001.

[31] S. Herranz, J. M. Rodríguez, H. J. Bussink et al., "Arrestinrelated proteins mediate $\mathrm{pH}$ signaling in fungi," Proceedings of the National Academy of Sciences of the United States of America, vol. 102, no. 34, pp. 12141-12146, 2005.

[32] S. K. Shenoy and R. J. Lefkowitz, "Receptor-specific ubiquitination of $\beta$-arrestin directs assembly and targeting of seventransmembrane receptor signalosomes," Journal of Biological Chemistry, vol. 280, no. 15, pp. 15315-15324, 2005.

[33] M. Becuwe, N. Vieira, D. Lara et al., "A molecular switch on an arrestin-like protein relays glucose signaling to transporter endocytosis," Journal of Cell Biology, vol. 196, no. 2, pp. 247259, 2012. 
[34] C. H. Lin, J. A. MacGurn, T. Chu, C. J. Stefan, and S. D. Emr, "Arrestin-related ubiquitin-ligase adaptors regulate endocytosis and protein turnover at the cell surface," Cell, vol. 135, no. 4, pp. 714-725, 2008.

[35] S. K. Shenoy, A. S. Modi, A. K. Shukla et al., " $\beta$-arrestindependent signaling and trafficking of 7 -transmembrane receptors is reciprocally regulated by the deubiquitinase $\mathrm{USP}_{33}$ and the $\mathrm{E}_{3}$ ligase Mdm2," Proceedings of the National Academy of Sciences of the United States of America, vol. 106, no. 16, pp. 6650-6655, 2009.

[36] S. K. Shenoy and R. J. Lefkowitz, "Trafficking patterns of $\beta$ arrestin and $\mathrm{G}$ protein-coupled receptors determined by the kinetics of $\beta$-arrestin deubiquitination," Journal of Biological Chemistry, vol. 278, no. 16, pp. 14498-14506, 2003.

[37] M. Berthouze, V. Venkataramanan, Y. Li, and S. K. Shenoy, "The deubiquitinases USP33 and USP20 coordinate $\beta 2$ adrenergic receptor recycling and resensitization," The EMBO Journal, vol. 28, no. 12, pp. 1684-1696, 2009.

[38] R. Kolling and C. P. Hollenberg, "The ABC-transporter Ste6 accumulates in the plasma membrane in a ubiquitinated form in endocytosis mutants," The EMBO Journal, vol. 13, no. 14, pp. 3261-3271, 1994.

[39] L. Hicke and H. Riezman, "Ubiquitination of a yeast plasma membrane receptor signals its ligand-stimulated endocytosis," Cell, vol. 84, no. 2, pp. 277-287, 1996.

[40] A. F. Roth and N. G. Davis, "Ubiquitination of the yeast afactor receptor," Journal of Cell Biology, vol. 134, no. 3, pp. 661-674, 1996.

[41] J. M. Galan, V. Moreau, B. Andre, C. Volland, and R. Haguenauer-Tsapis, "Ubiquitination mediated by the Npilp/Rsp5p ubiquitin-protein ligase is required for endocytosis of the yeast uracil permease," Journal of Biological Chemistry, vol. 271, no. 18, pp. 10946-10952, 1996.

[42] E. Lauwers, Z. Erpapazoglou, R. Haguenauer-Tsapis, and B. André, "The ubiquitin code of yeast permease trafficking," Trends in Cell Biology, vol. 20, no. 4, pp. 196-204, 2010.

[43] T. I. Strochlic, B. C. Schmiedekamp, J. Lee, D. J. Katzmann, and C. G. Burd, "Opposing activities of the snx3-retromer complex and ESCRT proteins mediate regulated cargo sorting at a common endosome," Molecular Biology of the Cell, vol. 19, no. 11, pp. 4694-4706, 2008.

[44] L. M. Traub, "Tickets to ride: selecting cargo for clathrinregulated internalization," Nature Reviews Molecular Cell Biology, vol. 10, no. 9, pp. 583-596, 2009.

[45] S. C. Shih, D. J. Katzmann, J. D. Schnell, M. Sutanto, S. D. Emr, and L. Hicke, "Epsins and Vps27p/Hrs contain ubiquitin-binding domains that function in receptor endocytosis," Nature Cell Biology, vol. 4, no. 5, pp. 389-393, 2002.

[46] R. C. Aguilar, H. A. Watson, and B. Wendland, "The yeast epsin Ent1 is recruited to membranes through multiple independent interactions," Journal of Biological Chemistry, vol. 278, no. 12, pp. 10737-10743, 2003.

[47] H. Barriere, C. Nemes, D. Lechardeur, M. KhanMohammad, K. Fruh, and G. L. Lukacs, "Molecular basis of oligoubiquitin-dependent internalization of membrane proteins in mammalian cells," Traffic, vol. 7, no. 3, pp. 282-297, 2006.

[48] M. Kazazic, V. Bertelsen, K. W. Pedersen et al., "Epsin 1 is involved in recruitment of ubiquitinated EGF receptors into clathrin-coated pits," Traffic, vol. 10, no. 2, pp. 235-245, 2009.

[49] S. Sigismund, T. Woelk, C. Puri et al., "Clathrin-independent endocytosis of ubiquitinated cargos," Proceedings of the
National Academy of Sciences of the United States of America, vol. 102, no. 8, pp. 2760-2765, 2005.

[50] M. R. Dores, J. D. Schnell, L. Maldonado-Baez, B. Wendland, and L. Hicke, "The function of yeast epsin and Ede1 ubiquitin-binding domains during receptor internalization," Traffic, vol. 11, no. 1, pp. 151-160, 2010.

[51] K. Haglund, N. Shimokawa, I. Szymkiewicz, and I. Dikic, "Cbl-directed monoubiquitination of CIN85 is involved in regulation of ligand-induced degradation of EGF receptors," Proceedings of the National Academy of Sciences of the United States of America, vol. 99, no. 19, pp. 12191-12196, 2002.

[52] M. Katz, K. Shtiegman, P. Tal-Or et al., "Ligand-independent degradation of epidermal growth factor receptor involves receptor ubiquitylation and Hgs, an adaptor whose ubiquitin-interacting motif targets ubiquitylation by Nedd4," Traffic, vol. 3, no. 10, pp. 740-751, 2002.

[53] S. Polo, S. Sigismund, M. Faretta et al., "A single motif responsible for ubiquitin recognition and monoubiquitination in endocytic proteins," Nature, vol. 416, no. 6879, pp. 451-455, 2002.

[54] S. B. Shields and R. C. Piper, "How Ubiquitin Functions with ESCRTs," Traffic, vol. 12, no. 10, pp. 1306-1317, 2011.

[55] W. M. Henne, N. J. Buchkovich, and S. D. Emr, "The ESCRT pathway," Developmental Cell, vol. 21, no. 1, pp. 77-91, 2011.

[56] D. J. Katzmann, G. Odorizzi, and S. D. Emr, "Receptor downregulation and multivesicular-body sorting," Nature Reviews Molecular Cell Biology, vol. 3, no. 12, pp. 893-905, 2002.

[57] G. J. Strous, P. van Kerkhof, R. Govers, A. Ciechanover, and A. L. Schwartz, "The ubiquitin conjugation system is required for ligand-induced endocytosis and degradation of the growth hormone receptor," The EMBO Journal, vol. 15, no. 15 , pp. 3806-3812, 1996.

[58] O. Staub, I. Gautschi, T. Ishikawa et al., "Regulation of stability and function of the epithelial $\mathrm{Na}^{+}$channel $(\mathrm{ENaC})$ by ubiquitination," The EMBO Journal, vol. 16, no. 21, pp. 6325-6336, 1997.

[59] L. Hicke and R. Dunn, "Regulation of membrane protein transport by ubiquitin and ubiquitin-binding proteins," Annual Review of Cell and Developmental Biology, vol. 19, pp. 141-172, 2003.

[60] D. Mukhopadhyay and H. Riezman, "Proteasomeindependent functions of ubiquitin in endocytosis and signaling," Science, vol. 315, no. 5809, pp. 201-205, 2007.

[61] J. N. Hislop and M. von Zastrow, "Role of ubiquitination in endocytic trafficking of G-protein-coupled receptors," Traffic, vol. 12, no. 2, pp. 137-148, 2011.

[62] A. M. Hommelgaard, K. Roepstorff, F. Vilhardt, M. L. Torgersen, K. Sandvig, and B. van Deurs, "Caveolae: stable membrane domains with a potential for internalization," Traffic, vol. 6, no. 9, pp. 720-724, 2005.

[63] A. Marchese and J. L. Benovic, "Agonist-promoted ubiquitination of the G protein-coupled receptor CXCR4 mediates lysosomal sorting," Journal of Biological Chemistry, vol. 276, no. 49, pp. 45509-45512, 2001.

[64] A. K. Shukla, J. Kim, S. Ahn et al., "Arresting a transient receptor potential (TRP) channel: $\beta$-arrestin 1 mediates ubiquitination and functional down-regulation of TRPV4," Journal of Biological Chemistry, vol. 285, no. 39, pp. 3011530125, 2010.

[65] A. Simonin and D. Fuster, "Nedd4-1 and $\beta$-arrestin-1 are key regulators of $\mathrm{Na}^{+} / \mathrm{H}^{+}$exchanger 1 ubiquitylation, 
endocytosis, and function," Journal of Biological Chemistry, vol. 285, no. 49, pp. 38293-38303, 2010.

[66] A. Marchese, C. Raiborg, F. Santini, J. H. Keen, H. Stenmark, and J. L. Benovic, "The E3 ubiquitin ligase AIP4 mediates ubiquitination and sorting of the $\mathrm{G}$ protein-coupled receptor CXCR4," Developmental Cell, vol. 5, no. 5, pp. 709-722, 2003.

[67] D. Bhandari, J. Trejo, J. L. Benovic, and A. Marchese, "Arrestin-2 interacts with the ubiquitin-protein isopeptide ligase atrophin-interacting protein 4 and mediates endosomal sorting of the chemokine receptor CXCR4," Journal of Biological Chemistry, vol. 282, no. 51, pp. 36971-36979, 2007.

[68] D. Bhandari, S. L. Robia, and A. Marchese, “The E3 ubiquitin ligase atrophin interacting protein 4 binds directly to the chemokine receptor CXCR4 via a novel WW domainmediated interaction," Molecular Biology of the Cell, vol. 20, no. 5, pp. 1324-1339, 2009.

[69] R. Malik and A. Marchese, "Arrestin-2 interacts with the endosomal sorting complex required for transport machinery to modulate endosomal sorting of CXCR4," Molecular Biology of the Cell, vol. 21, no. 14, pp. 2529-2541, 2010.

[70] O. Staub, S. Dho, P. C. Henry et al., "WW domains of Nedd4 bind to the proline-rich PY motifs in the epithelial $\mathrm{Na}^{+}$ channel deleted in Liddle's syndrome," The EMBO Journal, vol. 15, no. 10, pp. 2371-2380, 1996.

[71] S. Léon and R. Haguenauer-Tsapis, "Ubiquitin ligase adaptors: regulators of ubiquitylation and endocytosis of plasma membrane proteins," Experimental Cell Research, vol. 315, no. 9, pp. 1574-1583, 2009.

[72] F. T. Lin, Y. Daaka, and R. J. Lefkowitz, “ $\beta$-arrestins regulate mitogenic signaling and clathrin-mediated endocytosis of the insulin-like growth factor I receptor," Journal of Biological Chemistry, vol. 273, no. 48, pp. 31640-31643, 1998.

[73] L. Girnita, S. K. Shenoy, B. Sehat et al., " $\beta$-arrestin is crucial for ubiquitination and down-regulation of the insulin-like growth factor- 1 receptor by acting as adaptor for the MDM2 E3 ligase," Journal of Biological Chemistry, vol. 280, no. 26, pp. 24412-24419, 2005.

[74] V. Lakshmikanthan, L. Zou, J. I. Kim et al., "Identification of $\beta$ Arrestin2 as a corepressor of androgen receptor signaling in prostate cancer," Proceedings of the National Academy of Sciences of the United States of America, vol. 106, no. 23, pp. 9379-9384, 2009.

[75] J. Granzin, U. Wilden, H. W. Choe, J. Labahn, B. Krafft, and G. Buldt, "X-ray crystal structure of arrestin from bovine rod outer segments," Nature, vol. 391, no. 6670, pp. 918-921, 1998.

[76] M. Han, V. V. Gurevich, S. A. Vishnivetskiy, P. B. Sigler, and C. Schubert, "Crystal structure of $\beta$-arrestin at $1.9 \AA$ : possible mechanism of receptor binding and membrane translocation," Structure, vol. 9, no. 9, pp. 869-880, 2001.

[77] J. A. Hirsch, C. Schubert, V. V. Gurevich, and P. B. Sigler, "The $2.8 \AA$ crystal structure of visual arrestin: a model for arrestin's regulation," Cell, vol. 97, no. 2, pp. 257-269, 1999.

[78] S. K. Milano, H. C. Pace, Y. M. Kim, C. Brenner, and J. L. Benovic, "Scaffolding functions of arrestin-2 revealed by crystal structure and mutagenesis," Biochemistry, vol. 41, no. 10, pp. 3321-3328, 2002.

[79] S. K. Milano, Y. M. Kim, F. P. Stefano, J. L. Benovic, and C. Brenner, "Nonvisual arrestin oligomerization and cellular localization are regulated by inositol hexakisphosphate binding," Journal of Biological Chemistry, vol. 281, no. 14, pp. 9812-9823, 2006.
[80] R. B. Sutton, S. A. Vishnivetskiy, J. Robert et al., "Crystal structure of cone arrestin at $2.3 \AA$ : evolution of receptor specificity," Journal of Molecular Biology, vol. 354, no. 5, pp. 1069-1080, 2005.

[81] H. Shi, R. Rojas, J. S. Bonifacino, and J. H. Hurley, "The retromer subunit Vps26 has an arrestin fold and binds Vps35 through its C-terminal domain," Nature Structural and Molecular Biology, vol. 13, no. 6, pp. 540-548, 2006.

[82] B. M. Collins, S. J. Norwood, M. C. Kerr et al., "Structure of Vps26B and mapping of its interaction with the retromer protein complex," Traffic, vol. 9, no. 3, pp. 366-379, 2008.

[83] N. A. Boase and J. M. Kelly, "A role for creD, a carbon catabolite repression gene from Aspergillus nidulans, in ubiquitination," Molecular Microbiology, vol. 53, no. 3, pp. 929-940, 2004.

[84] E. Nikko and H. R. B. Pelham, "Arrestin-mediated endocytosis of yeast plasma membrane transporters," Traffic, vol. 10, no. 12, pp. 1856-1867, 2009.

[85] E. Nikko, J. A. Sullivan, and H. R. B. Pelham, "Arrestin-like proteins mediate ubiquitination and endocytosis of the yeast metal transporter Smf1," EMBO Reports, vol. 9, no. 12, pp. 1216-1221, 2008.

[86] T. Andoh, Y. Hirata, and A. Kikuchi, "PY motifs of Rod1 are required for binding to Rsp5 and for drug resistance," FEBS Letters, vol. 525, no. 1-3, pp. 131-134, 2002.

[87] Y. Kee, W. Muñoz, N. Lyon, and J. M. Huibregtse, "The deubiquitinating enzyme Ubp2 modulates Rsp5-dependent Lys $^{63}$-linked polyubiquitin conjugates in Saccharomyces cerevisiae," Journal of Biological Chemistry, vol. 281, no. 48, pp. 36724-36731, 2006.

[88] R. Gupta, B. Kus, C. Fladd et al., "Ubiquitination screen using protein microarrays for comprehensive identification of Rsp5 substrates in yeast," Molecular Systems Biology, vol. 3, article 116, 2007.

[89] A. Herrador, S. Herranz, D. Lara, and O. Vincent, "Recruitment of the ESCRT machinery to a putative seventransmembrane-domain receptor is mediated by an arrestinrelated protein," Molecular and Cellular Biology, vol. 30, no. 4, pp. 897-907, 2010.

[90] R. Hatakeyama, M. Kamiya, T. Takahara, and T. Maeda, "Endocytosis of the aspartic acid/glutamic acid transporter Dip5 is triggered by substrate-dependent recruitment of the Rsp5 ubiquitin ligase via the arrestin-like protein Aly2," Molecular and Cellular Biology, vol. 30, no. 24, pp. 5598-5607, 2010.

[91] N. Belgareh-Touzé, S. Léon, Z. Erpapazoglou, M. StawieckaMirota, D. Urban-Grimal, and R. Haguenauer-Tsapis, "Versatile role of the yeast ubiquitin ligase Rsp5p in intracellular trafficking," Biochemical Society Transactions, vol. 36, part 5, pp. 791-796, 2008.

[92] J. A. MacGurn, P.-C. Hsu, M. B. Smolka, and S. D. Emr, "TORC1 regulates endocytosis via npr1-mediated phosphoinhibition of a ubiquitin ligase adaptor," Cell, vol. 147, no. 5, pp. 1104-1117, 2011.

[93] A. F. O’Donnell, A. Apffel, R. G. Gardner, and M. S. Cyert, " $\alpha$-arrestins Aly1 and Aly2 regulate intracellular trafficking in response to nutrient signaling," Molecular Biology of the Cell, vol. 21, no. 20, pp. 3552-3566, 2010.

[94] J. F. Nabhan, R. Hu, R. S. Oh, S. N. Cohen, and Q. Lu, "Formation and release of arrestin domain-containing protein 1mediated microvesicles (ARMMs) at plasma membrane by recruitment of TSG101 protein," Proceedings of the National 
Academy of Sciences of the United States of America, vol. 109, no. 11, pp. 4146-4151, 2012.

[95] J. F. Nabhan, H. Pan, and Q. Lu, "Arrestin domain-containing protein 3 recruits the NEDD4 E3 ligase to mediate ubiquitination of the $\beta_{2}$-adrenergic receptor," EMBO Reports, vol. 11, no. 8, pp. 605-611, 2010.

[96] S. Rauch and J. Martin-Serrano, "Multiple interactions between the ESCRT machinery and arrestin-related proteins: implications for PPXY-dependent budding," Journal of Virology, vol. 85, no. 7, pp. 3546-3556, 2011.

[97] P. Zhang, C. Wang, K. Gao et al., "The ubiquitin ligase itch regulates apoptosis by targeting thioredoxin-interacting protein for ubiquitin-dependent degradation," Journal of Biological Chemistry, vol. 285, no. 12, pp. 8869-8879, 2010.

[98] H. Storez, M. G. H. Scott, H. Issafras et al., "Homo- and hetero-oligomerization of $\beta$-arrestins in living cells," Journal of Biological Chemistry, vol. 280, no. 48, pp. 40210-40215, 2005.

[99] K. M. Draheim, H. B. Chen, Q. Tao, N. Moore, M. Roche, and S. Lyle, "ARRDC3 suppresses breast cancer progression by negatively regulating integrin $\beta 4$," Oncogene, vol. 29 , no. 36, pp. 5032-5047, 2010.

[100] M. A. Peñalva, J. Tilburn, E. Bignell, and H. N. Arst Jr., "Ambient $\mathrm{pH}$ gene regulation in fungi: making connections," Trends in Microbiology, vol. 16, no. 6, pp. 291-300, 2008.

[101] M. Hayashi, T. Fukuzawa, H. Sorimachi, and T. Maeda, "Constitutive activation of the $\mathrm{pH}$-responsive Rim101 pathway in yeast mutants defective in late steps of the MVB/ESCRT pathway," Molecular and Cellular Biology, vol. 25, no. 21, pp. 9478-9490, 2005.

[102] W. Xu, F. J. Smith Jr., R. Subaran, and A. P. Mitchell, "Multivesicular body-ESCRT components function in $\mathrm{pH}$ response regulation in Saccharomyces cerevisiae and Candida albicans," Molecular Biology of the Cell, vol. 15, no. 12, pp. 5528-5537, 2004.

[103] J. H. Boysen and A. P. Mitchell, "Control of Bro1-domain protein Rim20 localization by external $\mathrm{pH}$, ESCRT machinery, and the Saccharomyces cerevisiae Rim101 pathway," Molecular Biology of the Cell, vol. 17, no. 3, pp. 1344-1353, 2006.

[104] A. Galindo, A. M. Calcagno-Pizarelli, H. N. Arst Jr., and M. Á. Peñalva, "An ordered pathway for the assembly of fungal ESCRT-containing ambient $\mathrm{pH}$ signalling complexes at the plasma membrane," Journal of Cell Science, vol. 125, no. 7, pp. 1784-1795, 2012.

[105] L. Kuo and E. O. Freed, "ARRDC1 as a mediator of microvesicle budding," Proceedings of the National Academy of Sciences of the United States of America, vol. 109, no. 11, pp. 4025-4026, 2012.

[106] E. Morita, "Differential requirements of mammalian ESCRTs in multivesicular body formation, virus budding and cell division," The FEBS Journal, vol. 279, no. 8, pp. 1399-1406, 2012.

[107] S. K. Shenoy, L. S. Barak, K. Xiao et al., "Ubiquitination of $\beta$-arrestin links seven-transmembrane receptor endocytosis and ERK activation," Journal of Biological Chemistry, vol. 282, no. 40, pp. 29549-29562, 2007.

[108] R. H. Oakley, S. A. Laporte, J. A. Holt, M. G. Caron, and L. S. Barak, "Differential affinities of visual arrestin, $\beta$ arrestin1, and $\beta$ arrestin 2 for $G$ protein-coupled receptors delineate two major classes of receptors," Journal of Biological Chemistry, vol. 275, no. 22, pp. 17201-17210, 2000.
[109] E. V. Gurevich and V. V. Gurevich, "Arrestins: ubiquitous regulators of cellular signaling pathways," Genome Biology, vol. 7, no. 9, article 236, 2006.

[110] A. Hervás-Aguilar, A. Galindo, and M. A. Peñalva, "Receptorindependent ambient $\mathrm{pH}$ signaling by ubiquitin attachment to fungal arrestin-like PalF," Journal of Biological Chemistry, vol. 285, no. 23, pp. 18095-18102, 2010.

[111] T. Hunter, "The age of crosstalk: phosphorylation, ubiquitination, and beyond," Molecular Cell, vol. 28, no. 5, pp. 730738, 2007.

[112] F. T. Lin, K. M. Krueger, H. E. Kendall et al., "Clathrinmediated endocytosis of the $\beta$-adrenergic receptor is regulated by phosphorylation/dephosphorylation of $\beta$-arrestin1," Journal of Biological Chemistry, vol. 272, no. 49, pp. 3105131057, 1997.

[113] F. T. Lin, W. Chen, S. Shenoy, M. Cong, S. T. Exum, and R. J. Lefkowitz, "Phosphorylation of $\beta$-arrestin2 regulates its function in internalization of $\beta_{2}$-adrenergic receptors," Biochemistry, vol. 41, no. 34, pp. 10692-10699, 2002.

[114] A. Kiselev, M. Socolich, J. Vinos, R. W. Hardy, C. S. Zuker, and R. Ranganathan, "A molecular pathway for lightdependent photoreceptor apoptosis in Drosophila," Neuron, vol. 28, no. 1, pp. 139-152, 2000.

[115] F. T. Lin, W. E. Miller, L. M. Luttrell, and R. J. Lefkowitz, "Feedback regulation of $\beta$-arrestin1 function by extracellular signal- regulated kinases," Journal of Biological Chemistry, vol. 274, no. 23, pp. 15971-15974, 1999.

[116] J. Gomez-Raja and D. A. Davis, "The $\beta$-arrestin-like protein Rim8 is hyperphosphorylated and complexes with Rim21 and Rim101 to promote adaptation to neutral-alkaline $\mathrm{pH}$," Eukaryotic Cell, vol. 11, no. 5, pp. 683-693, 2012. 

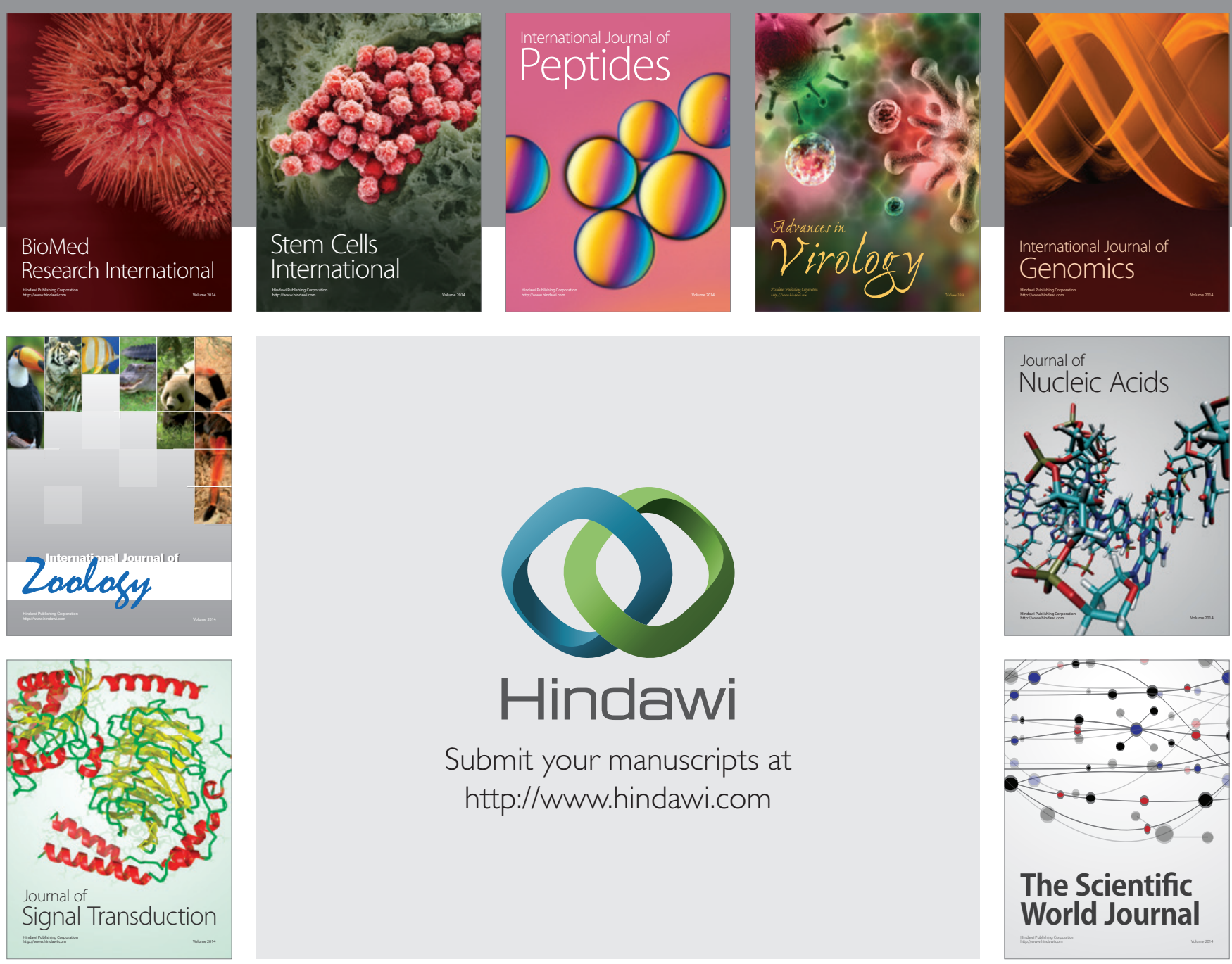

Submit your manuscripts at

http://www.hindawi.com
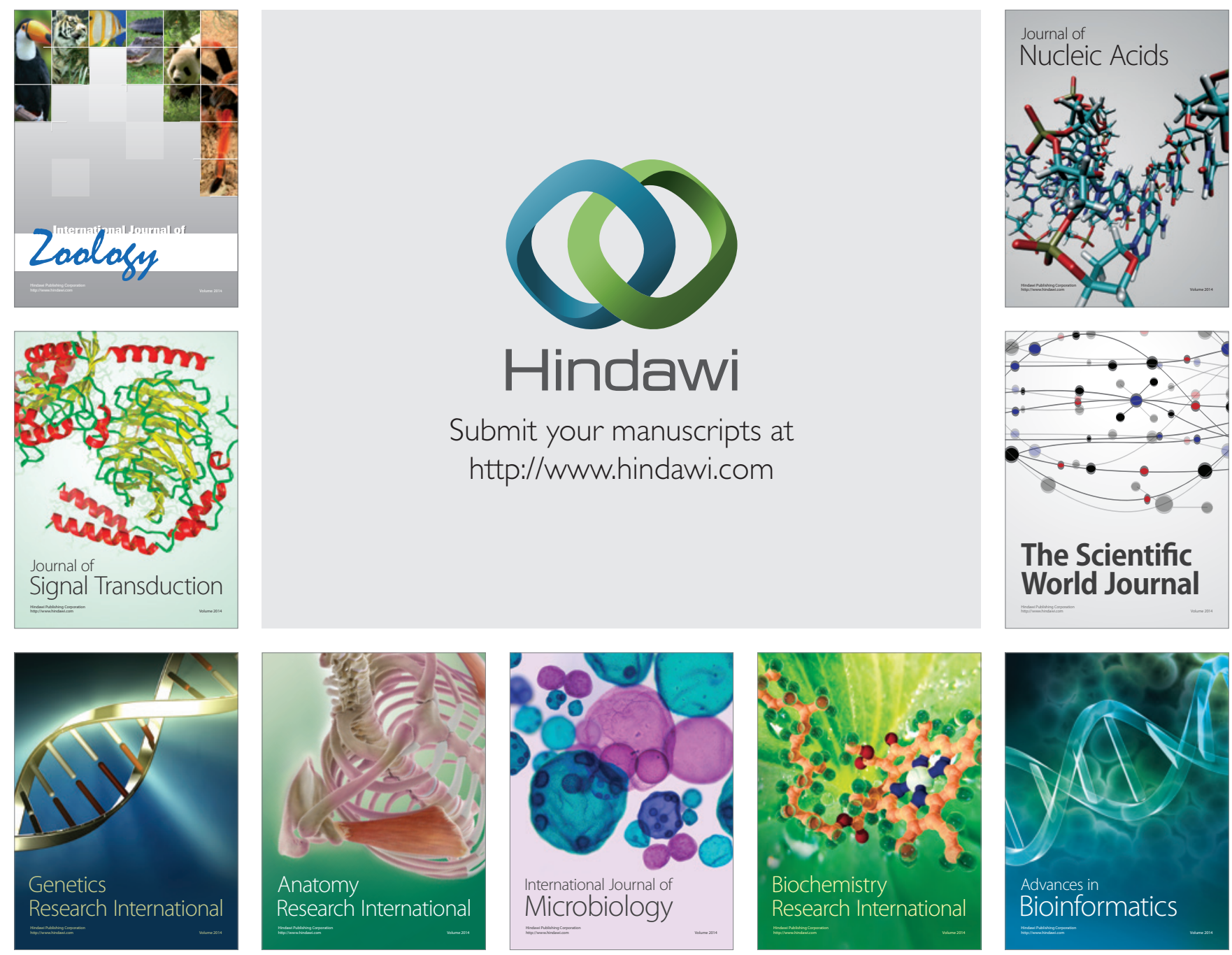

The Scientific World Journal
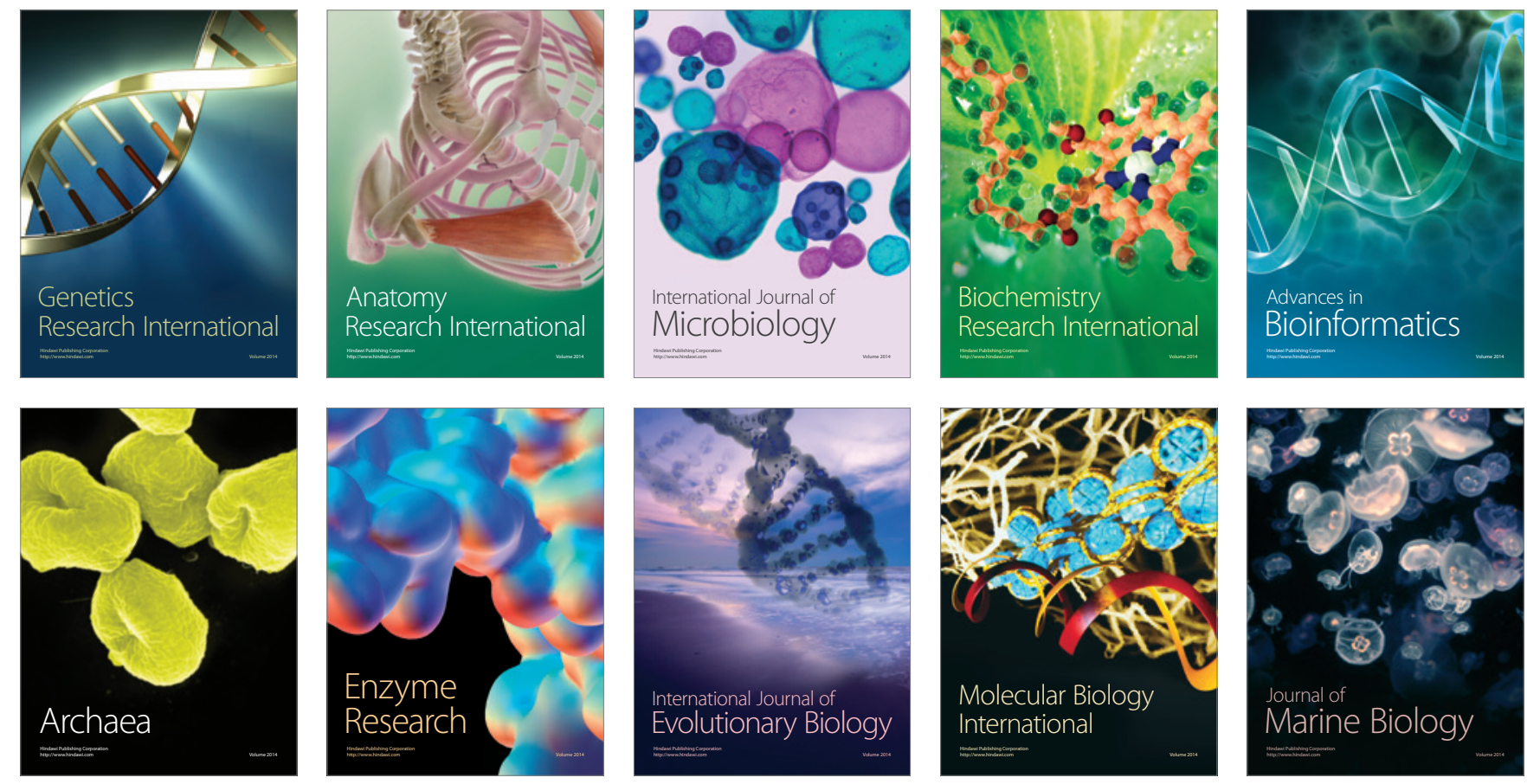